\section{AB0134 1 SERUM LL-37, GALECTIN-3, AND TOLL-LIKE RECEPTORS-3 LEVELS DECREASE IN PATIENTS WITH SYSTEMIC LUPUS ERYTHEMATOSUS}

A. Karatas ${ }^{1}$, R. F. Akkoc ${ }^{2}$, S. S. Koca ${ }^{1} .{ }^{1}$ Firat University, Rheumatology, Elazig, Turkey; ${ }^{2}$ Firat University, Anatomy, Elazig, Turkey

Background: Systemic lupus erythematosus (SLE) is a systemic inflammatory disease characterized by heterogeneous clinical manifestations (1). Although there are significant developments with its pathogenesis, it is still not fully known. In recent years, pathways such as NETosis and plasmacytoid dendritic cell (pDC) activation have been emphasized in the pathogenesis of $\operatorname{SLE}(2,3)$.

Objectives: In our study, we aimed to investigate serum LL-37, Galectin-3, and Toll-like receptors-3 (TLR)-3 levels, which are thought to be related to pathogenetic pathways in SLE patients.

Methods: 17 SLE patients and 33 healthy controls were included in the study The clinical and laboratory features of the patients were determined. Serum LL-37, Galectin-3, and TLR-3 levels were determined by ELISA (enzyme-linked immunosorbent assay) method using the appropriate commercial kit, and the results were evaluated according to the manufacturer's instructions.

Results: The clinical and laboratory features of the groups are described in Table 1. In our study, serum LL-37, Galectin-3, and TLR-3 levels were decreased statistically significantly in SLE patients compared to healthy control $(p=0.007$, $p=0.002$, and $p=0.008$, respectively).

Table 1. Clinical and laboratory features of the groups in the study

\begin{tabular}{lccc}
\hline & Healthy control $(\mathbf{n}=\mathbf{3 3})$ & $\begin{array}{c}\text { SLE } \\
(\mathbf{n}=\mathbf{1 7})\end{array}$ & $p$ \\
\hline Age (years) & $34.1 \pm 3.7$ & $40 \pm 11.4$ & 0.05 \\
Sex (n; female/male) & $33 / 0$ & $17 / 0$ & \\
LL-37(ng/ml) & $78.6 \pm 92.6$ & $14.2 \pm 19.3$ & 0.007 \\
Galectin-3 (ng/ml) & $25.5 \pm 23.2$ & $6.7 \pm 7.6$ & 0.002 \\
Toll-like receptors-3 (pg/ml) & $7893.4 \pm 1041.3$ & $916.2 \pm 469.7$ & 0.008 \\
\hline
\end{tabular}

Conclusion: It is suggested that LL-37, galectin- 3 , and TLR-3 levels have various effects on NEtosis and pDc activation pathways in SLE pathogenesis. In our study, low levels of serum LL-37, galectin-3, and TLR-3 in SLE patients suggest that they are associated with SLE pathogenesis.

References:

[1] Aringer M, Schneider M. [Systemic lupus erythematosus]. Dtsch Med Wochenschr.

2016:141:537-43

[2] Panda SK, Kolbeck R, Sanjuan MA. Plasmacytoid dendritic cells in autoimmunity. Curr Opin Immunol. 2017;44:20-25.

[3] van der Linden M, van den Hoogen LL, Westerlaken GHA, Fritsch-Stork RDE, van Roon JAG, Radstake TRDJ, Meyaard L. Neutrophil extracellular trap release is associated with antinuclear antibodies in systemic lupus erythematosus and anti-phospholipid syndrome. Rheumatology (Oxford). 2018;57:1228-1234.

Disclosure of Interests: None declared

DOI: 10.1136/annrheumdis-2020-eular.5782

\section{AB0135 1 THE MITOCHONDRIAL-RETICULAR NETWORK (MRN) OF NEUTROPHILIC LEUKOCYTES OF SYNOVIAL FLUID (SF) OF PATIENTS WITH SLE AND RA}

G. V. Kudriavtseva ${ }^{1}$, Y. Malenkov ${ }^{2}$, V. Shishkin ${ }^{1}$, V. V. Shishkin ${ }^{1} .{ }^{1}$ Saint Petersbuwg State University, Saint Petersburg, Russian Federation; ${ }^{2}$ Saint Petersburg State University, Sankt-Peterburg, Russian Federation

\section{Background:}

Objectives: It has been established that in cells, in particular in neutrophilic leukocytes of SF, mitochondria form a mitochondrial-reticular dynamic spatial network (MRN). MRN is the epicenter of apoptosis, reflecting structural and functional changes in the immuno-complex pathology in SLE and RA.

Methods: SF was analyzed in patients: 10 SLE $(43 \pm 2.3$ years), 13 RA (45 \pm 1.6 years) and 8 donors $(42 \pm 3.7$ years, postmortem). Neutrophilic leukocytes from the SF were isolated by standard methods and resuspended in a composition medium: $70 \mathrm{mM} \mathrm{NaCl} ; 140 \mathrm{mM}$ sucrose; $5.6 \mathrm{mM} \mathrm{KCl} ; 10 \mathrm{mM}$ pyruvate; $8 \mathrm{mM}$ MOPS; $\mathrm{pH}=7.4$. The cell suspension was centrifuged for $5 \mathrm{~min}$ at $800 \mathrm{~g}$. MRN was isolated by centrifuging the resulting supernatant for $15 \mathrm{~min}$ at $12000 \mathrm{~g}$. The resulting MRN fragments were resuspended in citrate-phosphate buffer $(\mathrm{pH}=7.4)$ and used in experiments. The activity of adenosine monophosphate-activated protein kinase (AMPK) was evaluated by Western blotting. Quantitative determination of cytochrome C (Cyt C) was carried out by enzyme immunoassay method using the Human Cytochrome c Platinum ELISA kit (eBioscience, USA). Active forms of oxygen free radicals (AFRF) were registered by EPR. The swelling rate of MRN fragments was determined spectrophotometrically at $540 \mathrm{~nm}$. The electrophoretic mobility (EM) of MRN fragments was determined by the automatic microscope "Parmoquant-2".

Results: MRN of neutrophilic leukocytes of the SF undergoes significant adaptive rearrangements during the development of SLE and RA (tab.1). On average, the expression of biochemical indicators of autophagy (AMPK), apoptosis (Cyt. C), necrosis (level of oxygen free radicals, low-amplitude swelling rate) increases by 2-3 times compared with the conventional norm. Particular attention should be paid to pathological changes in the electrokinetic potential of MRN, which determines the functional state of the SF as a whole as a colloidal system. Obviously, in SLE and RA, depletion of the energy of MRN (a sharp increase in the activity of AMRK), activation of free radical processes, disruption of intracellular ion homeostasis due to an increase in the rate of swelling of MRN as a manifestation of a compensatory-adaptive reaction. It ultimately leads to a decrease in electrokinetic properties of MRN. Thus EM is an integral indicator of physico-chemical properties and architectonics of MRN pointing to the development of autoimmune pathology.

Table 1. EXPRESSION OF INDUCTORS OF AUTOPHAGY, APOPTOSIS, NECROSIS AND ELECTROPHORETIC MOBILITY OF MRN FRAGMENTS OF NEUTROPHILIC LEUKOCYTES OF SF IN SLE AND RA

\begin{tabular}{|c|c|c|c|c|c|}
\hline $\begin{array}{l}\text { Experience } \\
\text { Terms }\end{array}$ & $\begin{array}{c}\text { AMPK, } \\
\text { cond.unit/mg } \\
\text { protein }\end{array}$ & $\begin{array}{l}\text { Cyt C, } \\
\mathrm{ng} / \mathrm{ml}\end{array}$ & $\begin{array}{l}\text { AFRF, unit/mg } \\
\text { protein }\end{array}$ & $\begin{array}{l}\text { Swelling rate of } \\
\text { MRN, } \\
\text { /min. } \\
\text { mg protein }\end{array}$ & $\begin{array}{c}\mathrm{EM}, \\
\mathrm{m} / \mathrm{v} \cdot \mathrm{sec}\end{array}$ \\
\hline Donor (8) & $0,51 \pm 0,05$ & $23,7 \pm 5,4$ & $7,3 \pm 2,4$ & $0,177 \pm 0,004$ & $1,58 \pm 0,07$ \\
\hline SLE (10) & $1,73 \pm 0,04^{\star \star}$ & $49,3 \pm 6,5^{*}$ & $21,3 \pm 5,1^{\star \star}$ & $0,435 \pm 0,005^{\star \star \star}$ & $0,35 \pm 0,05^{\star \star \star}$ \\
\hline$R A(13)$ & $1,25 \pm 0,07^{\star \star}$ & $47,8 \pm 4.8^{*}$ & $15,7 \pm 4,3^{*}$ & $0,410 \pm 0,007^{\star \star \star}$ & $0,41 \pm 0,07^{\star \star *}$ \\
\hline
\end{tabular}

Conclusion: Endoplasmic stress occurs in SF cells during the development of SLE and RA, blocking of autophagy and apoptosis leads to a breakdown of neutrophilic leukocyte MRN, accumulation of high molecular products of tissue decay - phlogogens in the intercellular space, among which the expression in the context is characterized by proteins - chaperones Hsp 60-100. These processes are accompanied by a shift in the bioelectric homeostasis of MRN neutrophilic leukocytes, an increase in their swelling rate and a significant decrease in their electrokinetic potential. The described MRN reactions of neutrophilic leukocytes of the SF should be taken into account when developing pharmacologically induced apoptosis as a new approach in the treatment of autoimmune diseases

References:

[1] Shishkin V. I. et al. Ann Rheum Dis 2017; 76: No 6, p.1077-1078; DOI:10.1136/ annrheumdis-2017-eular5364

Disclosure of Interests: None declared

DOI: 10.1136/annrheumdis-2020-eular.1258

\section{AB0136 THE SUSTAINED POSITIVITY FOR ANTI-DSDNA ANTIBODIES FOSTERS THE ESTABLISHMENT OF AN ATHEROTHROMBOTIC STATUS IN PATIENTS WITH SYSTEMIC LUPUS ERYTHEMATOSUS}

A. M. Patiño-Trives' ${ }^{1}$, M. A. Aguirre ${ }^{1}$, C. Pérez Sánchez ${ }^{1}$, P. S. Laura' ${ }^{1}$, M. LuqueTévar $^{1}$, I. Arias de la Rosa ${ }^{1}$, R. Ortega Castro ${ }^{1}$, M. D. C. Abalos-Aguilera ${ }^{1}$, M. Espinosa' ${ }^{1}$, P. Seguí Azpilcueta ${ }^{1}$, J. O. Pers ${ }^{2}$, N. Barbarroja Puerto ${ }^{1}$ M. Alarcon-Riquelme ${ }^{3}$, E. Collantes Estevez ${ }^{1}$, C. Lopez-Pedrera ${ }^{1} .{ }^{1} / \mathrm{MIBIC/}$ Reina Sofia Hospital/University of Cordoba, Cordoba, Spain; ${ }^{2}$ Université de Brest, Brest, France; ${ }^{3}$ Center for Genomics and Oncological Research (GENYO), Granada, Spain

\section{Background:}

Objectives: 1. This study, developed within the Innovative Medicines Initiative Joint Undertaking project PRECISESADS framework, aimed to identify specific molecular profiles involved in the enhanced CV-risk present in SLE patients and to analyze the relevance of the sustained positivity for anti-dsDNA on the establishment of their atherothrombotic status.

Methods: One hundred and twenty-four SLE consecutive patients (not including patients with associated antiphospholipid syndrome), belonging to the PRECISESADS project, were evaluated for the presence of CVD and its association with positivity for anti-dsDNA antibodies. A second cohort of 62 SLE patients was included, of which endothelial dysfunction, lipid profile, the presence of atheroma plaques (identified by a pathologic increase in the carotid intimae media thickness -CIMT-), and the frequencies of anti-dsDNA positivity for 7 years, were evaluated. Serum inflammatory and oxidative stress biomolecules, and 